\title{
Tree ring effects and ice core acidities clarify the volcanic record of the first millennium
}

\author{
M. G. L. Baillie ${ }^{1}$ and J. McAneney ${ }^{2}$ \\ ${ }^{1}$ School of Geography, Archaeology and Palaeoecology, Elmwood Avenue, Queen's University, Belfast, \\ Belfast BT7 1NN, Northern Ireland, UK \\ ${ }^{2}$ Independent Researcher, Bangor, Northern Ireland, UK
}

Correspondence to: M. G. L. Baillie (m.baillie@qub.ac.uk)

Received: 28 February 2014 - Published in Clim. Past Discuss.: 15 April 2014

Revised: 8 December 2014 - Accepted: 12 December 2014 - Published: 16 January 2015

\begin{abstract}
In 2012 Plummer et al., in presenting the volcanic chronology of the Antarctic Law Dome ice core, chose to list connections to acid layers in other ice cores and also possible chronological coincidences between ice acid dates and the precise dates of frost damage, and/or reduced growth in North American bristlecone pines. We disagree with the chronological links indicated by Plummer et al. for the period before $\mathrm{AD} 700$, and in this paper we show that a case can be made that better linkages between ice acid and tree ring effects occur for this period if the ice chronologies are systematically moved forward by around 7 years, consistent with a hypothesis published by Baillie in 2008. In the paper we seek to explore the proposition that frost damage rings in North American bristlecone pines are a very useful indicator of the dates of certain large explosive volcanic eruptions; the dating of major eruptions being critical for any clear understanding of volcanic forcing. This paper cannot prove that there is an error in the Greenland Ice Core Chronology 2005 (GICC05), and in equivalent ice chronologies from the Antarctic, however, it does provide a coherent argument for an apparent ice dating offset. If the suggested offset were to prove correct it would be necessary to locate where the error occurs in the ice chronologies and in this regard the dating of the increasingly controversial Icelandic Eldgjá eruption in the AD 930s, and the China/Korean Millennium eruption which occurs some 7 years after Eldgjá, may well be critical. In addition, if the offset were to be substantiated it would have implications for the alleged identification of tephra at $429.3 \mathrm{~m}$ in the Greenland GRIP core, currently attributed to the Italian volcano Vesuvius and used as a critical zero error point in the GICC05 chronology.
\end{abstract}

\section{Background}

Large explosive volcanic eruptions can induce hemispheric, and occasionally global, environmental effects through the injection of sulfate aerosols into the stratosphere altering the absorption and reflection of solar radiation within the atmosphere, producing an overall cooling effect on global climate (Rampino and Self, 1982). Attempts to trace the areal extent of such environmental effects rely mostly on evidence of tree growth response to climate derived from precisely dated tree ring chronologies. For example, Briffa et al. (1998) investigated the relationship between maximum latewood density (MXD) in high-latitude and high-elevation conifers from around the Northern Hemisphere and historical eruptions, while Scuderi (1990) assessed growth minima in foxtail pines from the Sierra Nevada against volcanic records back to $1000 \mathrm{BC}$.

In 1984 LaMarche and Hirschboeck postulated a relationship between frost rings (damage caused by unseasonal frost during the growing season) in high-elevation bristlecone pines from the western United States and explosive volcanism. They suggested that climatic dislocation caused by high-altitude volcanic aerosols could cause unseasonal cold air to move down the Rockies freezing still growing trees, leaving visible scarring. Although they were able to show reasonable linkages between frost rings and volcanoes in recent times (for example they noted frost rings in 1912 the year of the Katmai eruption in Alaska, and in the years 1884, $1837,1817,1680,1640$ and 1601, each within 1 or 2 years of known eruptions), this relationship tended to break down further back in time when comparisons were made with volcanic evidence deduced from ice cores, in the absence of his- 
torically dated volcanoes. This early attempt at linking tree ring effects and ice core acidities was elaborated further by Salzer and Hughes (2007) who provided lists of frost ring and narrow ring dates back to 5000 years ago, while highlighting tree effects that occurred within 5 years of ice core acidity dates.

From such work certain dates for explosive volcanism stand out, for example, AD 1640, AD 1601 and AD 1257 are represented as acid layers in the Greenland Crête and the Greenland Ice Core Project (GRIP) ice cores (Hammer et al., 1980; Clausen et al., 1997), they show up in the Greenland Ice Sheet project (GISP2) core at $1603 \pm 2,1642 \pm 2$ and $1259 \pm 2$ (Zielinski, 1995), in the North Greenland Eemian Ice Drilling "NEEM-2011-S1" (hereafter NEEM S1) and West Antarctic Ice Sheet Divide (WDC06A) cores (Sigl et al., 2013) and in the Antarctic Law Dome (Plummer et al., 2012), Dronning Maud Land (DML) (Traufetter et al., 2004), and South Pole (Ferris et al., 2011) cores. This implies that these eruptions were equatorial. However, while trees register the effects of the 1640 and 1601 eruptions widely (Briffa et al., 1998; Scuderi, 1990; Salzer and Hughes, 2007), the massive eruption, now believed to have taken place in $\mathrm{AD}$ 1257 and attributed to the Salamas volcano in Indonesia (Lavigne et al., 2013), shows up patchily in trees (Jones et al., 2013; D'Arrigo et al., 2013) with perhaps the clearest evidence for upset being provided by bristlecone pine frost rings in 1257 and 1259 (Salzer and Hughes, 2007).

What emerges from this background is that bristlecone pine frost rings in high-elevation bristlecone pines from the western United States can be, as originally postulated by LaMarche and Hirschboeck (1984), used as sensitive indicators of explosive volcanism. Obviously the relationship is not one-to-one; not every volcano automatically produces frost damage in bristlecone pines, while some frost rings appear not to be related to volcanism. However, a case exists that numbers of key large volcanic events are associated with bristlecone pine frost rings (see Supplement). When these occur, the precise dating provided by dendrochronology makes frost ring dates important in any attempts to link to historical records of how human populations were affected. Unfortunately, the introduction of narrow ring dates by Salzer and Hughes (2007) served to complicate the relationship between volcanoes and tree ring effects. Narrow ring occurrences have the disadvantage that they can have a number of possible causes, in contrast to frost rings which appear unequivocally to be caused by anomalous, unseasonal extreme cold.

For example, if we look at a recent paper by Jones et al. (2013), where they assessed the worst 20 individual years in the last 7500 years using maximum latewood density (MXD) and tree ring width (TRW) in tree rings from Northern Fennoscandia, in relation to volcanic eruptions, their list of 20 dates includes the recent dates AD 1838, 1734, 1680, 1642 and 1601. Of these extreme tree ring events related to volcanoes, all five are also represented by frost rings in bristlecone pines (LaMarche and Hirschboeck, 1984; Salzer and Hughes, 2007) while only 1838 is singled out as a narrow ring event (Salzer and Hughes, 2007). Unfortunately by raising the issue of narrow rings Salzer and Hughes allowed researchers to pick tree ring phenomena - either frost rings or narrow rings - that occurred proximate to volcanic acid signals dated within the ice core chronologies, these links suggesting support for the dating of the ice cores (Plummer et al., 2012). Before analysing the deficiencies in this approach it is necessary to provide background on the issue of the ice core chronologies.

Long ice cores mostly exhibit clear annual layering. Visual inspection is supplemented by study of annually fluctuating chemical and isotopic signals that allow unequivocal identification of most annual layers. However, ice cores do suffer from periodic "problem layers" where uncertainty creeps into the layer counting. This is handled by adding $0.5 \pm 0.5$ years for each problem layer (Vinther et al., 2006) and by accumulating these problem layers an error figure is obtained for ancient dates. This procedure is short-circuited by attempts to identify traces of known volcanoes such as Öraefajökull (1362), Hekla 1 (1104) and Vesuvius (AD 79 ) in the ice. Indeed it is claimed that acid and tephra at 429.1/429.3 $\mathrm{m}$ in the GRIP ice core derived specifically from Vesuvius and provide a zero-error point in the ice chronologies (Barbante et al., 2013). While this sounds coherent, one key issue relates to independent replication of the ice acidity dates in Dye3, GRIP and NGRIP. Vinther et al. (2006) state that "The three ice core records have been synchronized using volcanic reference horizons". This involved identifying significant ECM signals and then independently counting the layers between the ECM signals. In our view this was a flawed procedure. True dating replication could only be achieved by counting the whole of each core independently. For comparison, in dendrochronology replication is often provided by comparing chronologies produced by independent workers in independent laboratories. This apparent lack of completely independent replication of the Dye3, GRIP and NGRIP cores makes the identification of Vesuvius tephra in the ice absolutely critical for the chronology of the European ice cores. That overall chronology, the Greenland Ice Core Chronology 2005 (GICC05), has been regarded as definitive since 2006 (Vinther et al., 2006).

The reason for rehearsing this history lies in the conclusion of the Vesuvius dating paper by Barbante et al. (2013). They state: "We identified volcanic glass fragments at $429.3 \mathrm{~m}$ depth where the elemental analysis strongly suggests that they originated from the 79 AD Vesuvius eruption." Given that there is a known controversy relating to the chronology of the European ice cores (Baillie, 2008, 2010) it is not clear that "strongly suggests" is sufficiently unequivocal with respect to this key identification of Vesuvius tephra. In this paper we are going to show that there are real grounds for doubt relating to the chronology of the main Greenland, and some of the Antarctic ice cores in the first millennium AD, 
Table 1. Comparison of intervals (given by the value between successive diamonds $[\boldsymbol{\nabla}]$ ) between volcanic acid layers in Law Dome, Antarctica (Plummer et al., 2012), and between frost rings in American bristlecone pines (Salzer and Hughes, 2007) in the sixth and seventh centuries. The similarity of the intervals suggests an average age offset of the Law Dome dates from the tree ring dates of 7.4 years.

\begin{tabular}{|c|c|c|c|c|}
\hline $\begin{array}{l}\text { Law Dome } \\
\text { acid date }\end{array}$ & $\begin{array}{c}\text { Law Dome } \\
\text { mean date }\end{array}$ & $\begin{array}{l}\text { Law Dome } \\
\text { spacing }\end{array}$ & $\begin{array}{c}\text { Frost ring } \\
\text { date }\end{array}$ & $\begin{array}{c}\text { Frost ring } \\
\text { spacing }\end{array}$ \\
\hline & & & 694 & \\
\hline & & & 692 & \\
\hline \multirow[t]{2}{*}{$679.2-681.1$} & 680.1 & $\diamond$ & 687 & $\diamond$ \\
\hline & & 3 years & & 3 years \\
\hline \multirow[t]{4}{*}{$676.5-677.7$} & 677.1 & $\diamond$ & 684 & $\diamond$ \\
\hline & & & 681 & \\
\hline & & 110.1 & 674 & 110 years \\
\hline & & & 627 & \\
\hline \multirow[t]{2}{*}{$566.3-567.7$} & 567.0 & $\diamond$ & 574 & $\diamond$ \\
\hline & & 34.9 years & & 33 years \\
\hline \multirow[t]{4}{*}{$530.9-533.2$} & 532.1 & $\diamond$ & 541 & $\diamond$ \\
\hline & & & 536 & \\
\hline & & & 532 & \\
\hline & & & 522 & \\
\hline
\end{tabular}

and these doubts, if substantiated, would call into question the identification of the tephra particles analysed by Barbante et al. (2013) and attributed to Vesuvius.

\section{Methodology}

The presentation of a list of Law Dome acidity dates from AD 1991.7 to 2.5 BC by Plummer et al. (2012, Table 1) with accompanying lists of parallel acidity dates, and dates for Northern Hemisphere tree ring signatures, provided an apparently coherent picture. Dates already mentioned, such as 1641, 1601 and 1257 are prominent in all records. However, in the period before AD 900 the suggested Law Dome to tree ring linkages pose a methodological problem. The clearest example lies in the sixth century. Plummer et al. (2012) suggest that a narrow ring at AD 569 might link to their 566.3 acidity and a frost ring at AD 532 might link to acid at 530.9. Yet Baillie (2008) had pointed out Greenland ice acidities at $515.5 \pm 2,529 \pm 2,533-534 \pm 2$ and $567 \pm 2$ (Clausen et al., 1997; Larsen et al., 2008) that appeared to fit better to bristlecone pine frost rings at 522, 536, 541 and 574. The Plummer et al. (2012) suggested linkages clearly support the ice core chronology, while the Baillie (2008) proposed linkages suggest a 7-year ice dating discrepancy. How are such issues to be resolved objectively?

A robust way of comparing two independent, highly stratified and contiguous chronologies, that potentially evidence the same discrete events, is through a direct comparison of spaced time intervals between the events. The spacing be- tween a series of frost rings (possibly forced by volcanic activity) and the spacing between a series of acid signals (definitely attributable to volcanic activity) would be a case in point. If a particular series of spaced events are found in both chronologies over an interval of centuries, then the two chronologies are in all likelihood recording the same events. To this effect, we have performed a spaced analysis in tree rings and a series of different ice cores including Law Dome, NEEM S1, WDC06A and DML, primarily for the period AD 500-700. The reasons for restricting the analysis to this time window in the first instance will be discussed below.

\section{Assessing the validity of suggested linkages between tree ring frost dates and Law Dome acidity dates}

The chronological issues outlined above, involving dated tree ring effects and dated ice core acidities, were thrown into sharp relief when Plummer et al. (2012) showed possible connections from ice acidities, in the Antarctic Law Dome core, to various tree ring phenomena. Given that tree rings are an absolute dating standard, this suggested connection of acid layers in the Law Dome ice core to tree ring effects (Table 1 in Plummer et al., 2012) served to give the impression that the ice dates conformed to the tree ring timescale. For the period AD 100 to 700 Plummer et al. (2012) selected ice acid links to five frost ring and five narrow-ring dates from a full listing of 32 frost ring and 25 narrow-ring dates (Salzer and Hughes, 2007, Table 1) in this six-century interval. This procedure of selecting a few dates from many potential targets is inherently weak and demands that a closer look be taken at assessing the significance of the suggested correlates.

Examining the linkage of Law Dome acidity to tree ring phenomena, Plummer et al. (2012) cite the tree effect at AD 674 as a growth minimum when in fact it is a frost ring date (Salzer and Hughes, 2007, Table 1). This typographical error suggests that Plummer et al. (2012) regard either growth minima or frost rings as equally indicative of extreme conditions; symptomatic of the blurring caused by Salzer and Hughes (2007) introducing minimal growth into the discussion. Next, in the selected tree ring dates that Plummer et al. (2012) indicate as possible links to ice acidities, the acidities beginning at AD 676.5 and 679.2 are only, on average, 3 years apart, yet they are linked to two features in tree ring records that are 7 years apart in 674 and 681 . Given that the acid is in stratified ice it is unlikely that the acidities could be separated by as much as 7 years, and it is also very unlikely that the tree ring effects are significantly lagged to allow volcanoes 3 years apart to produce frost rings 7 year apart. It can be inferred that this suggested ice-tree linkage cannot be correct. Thirdly, Plummer et al. (2012) link their Law Dome acid spike at $530.9_{-5}^{+1}$ to a Greenland acidity in the NGRIP core at $533 \pm 2$, and indicate a possible link to a frost ring in 532. This suggested linkage ignores the fact that Larsen et al. (2008) specifically attribute their NGRIP $533 \pm 2$ acid- 
ity to the now famous AD 536 global environmental event (Stothers, 1984; Baillie, 1994; Keys, 1999; Gunn, 2000; Arjava, 2005; Oppenheimer, 2011; Barras, 2014). Thus it cannot possibly, within the ice core literature, link to a frost ring in 532. Taken together, these points indicate that Plummer et al. (2012) in showing possible connections between ice core acidities and tree ring signatures, have taken a less than robust view of ice/tree-ring linkages and indicated only those links that, to an outside observer, appear to confirm the existing ice chronology placement. It is because of this that it is necessary to tackle the linkage issue with a different approach.

\section{New Law Dome linkages to tree ring effects}

First it is necessary to look at the issue of possible lags between the initiation of a volcanic event and the deposition of acid in Greenland or Antarctic ice cores, as well as lags between the insertion of acid into the stratosphere and the initiation of effects in trees. LaMarche and Hirschboeck (1984) pointed out that unseasonal frost damage might occur in the year of, or one or two years after the year of an eruption. However, the dates cited above relating to extreme tree ring density events in Fennoscandia indicate that frost rings tend not to be significantly lagged and mostly occur in the year of an eruption or 1 year after (Jones et al., 2013). Although it can take time for acid from an eruption to arrive on the icecaps, again there is little evidence of ice cores showing significant lags. The recent practice of defining the start and end points of acid deposition events (for example see Plummer et al., 2012; Sigl et al., 2013) means that derived dates can be given mostly for the years of eruptions. Irrespective of such considerations, in the discussion below the use of spaces between events radically reduces the need to consider the issue of lags in tree response and acid deposition.

The immediate starting point is to treat only with frost rings, with their implicit links to unusual extreme cold conditions. In Table 1 the dates for acid in the Law Dome core between AD 500 and 700 (Plummer et al., 2012) are tabulated against the full list of frost rings for those centuries from Salzer and Hughes (2007). In the table the spacing between both the ice acidities and the frost ring dates are given. Looking for consistent spacing between repeated events is an inherently more robust method of linking two sets of observations than picking single events. In Table 1 we see that the mean spacing between the Law Dome acid layers at ice dates 679.2-681.1 and 676.5-677.7 is almost exactly 3 years. We can see from the bristlecone-pine frost-ring list that there are intervals between frost rings of 2, 5, 3, 3 and 7 years available in the vicinity of the two Law Dome dates given by Plummer et al. (2012) as 679.2 and 676.5.

Looked at in isolation it might seem that the Plummer et al. (2012) choice of AD 681 and 674 frost rings as exemplar linkages is loosely acceptable. However, if we add the fact that their next acid layer down the core is dated by them to 566.3 , and the next to 530.9, it can quickly be shown that there is a more robust approach to choosing which couplet, from the $674,681,684,687,692,694$ frost rings, to link to the 679.2 and 676.5 acidities. The pair of frost rings chosen from this list is constrained to be around 3 years apart, and is also constrained to be close to 110 years after another ice acid to tree ring link; with that link in turn around 33 years after a third. These facts dictate that, instead of linking the ice dated acidities at 679.2 and 676.5 to frost rings at 681 and 674, they should in all likelihood be linked to the frost rings at $\mathrm{AD} 684$ and 687, see Table 1.

The ice spacing in Table 1 indicate that the frost ring intervals $3: 110: 33$ are mimicked almost exactly in the spacing of the Law Dome acidities, namely $3: 110.1: 34.9$, implying that the acidities should be moved forward on average 7.4 years to conform to the frost ring record, something exactly in line with the prior suggestion by Baillie (2008) regarding Greenland cores for the sixth century. Now, it could be argued that this is similar to what Plummer et al. (2012) did when they linked 679.2 to $681,676.5$ to $674,566.3$ to 569 and 530.9 to 532. But Plummer et al. (2012) did not simply use the bristlecone-pine frost-ring list; they also drew that one date, 569, from the less well-constrained (in terms of cause and effect) narrow-ring list provided by Salzer and Hughes (2007). Moreover, the resultant ice spacing intervals $3: 110.1: 34.9$ really are not close enough to their chosen tree-effect spacing intervals of $7: 105: 37$ to be acceptable, given the absolute nature of tree rings and the highly stratified ice over intervals as short as 2 centuries. We would claim that the results in Table 1 are inherently superior to those suggested, but not justified, by Plummer et al. (2012).

Having established that a spaced approach allows more robust linkages to be proposed between disparate but essentially annual records, a more detailed analysis was undertaken of the time interval between AD 500 and 700. There were several reasons for choosing this interval. One principal reason relates to the history of the ice cores. When the detailed list of acidities in the replicated Dye 3 and GRIP, Greenland, cores was published there was clearly good agreement between the cores down to AD 516 (Dye3) and 514 (GRIP) (Clausen et al., 1997). However, between AD 500 and AD 1 this agreement broke down - the only listed acidities being AD 178, 156, 80 and 47 (Dye3) and AD 159 and 79 (GRIP). Indeed, with the exception of the acidities at 80 (Dye3) and AD 79 (GRIP) which are now attributed to Vesuvius (Vinther et al., 2006; Barbante et al., 2013), there are no volcanic signals in Greenland ice that have been singled out as environmentally significant in the first half of the first millennium. Another reason for ignoring the period AD 100-500 is that while Plummer et al. show three Law Dome acid layers that coincide with frost rings within 2 years, on analysis (with 20 frost rings and 10 acid layers in 400 years) this rate of coincidence is not significantly different from that which might be expected by chance using a binomial proba- 
bility distribution. Thus the analysis here is restricted primarily to the period AD 500-700, though this will be extended to the first century BC in subsequent discussion.

\section{Extending the spaced analysis to acidities in the NEEM S1 core}

The results in Table 1 were sufficiently encouraging to suggest a more extended spacing comparison between bristlecone pine frost rings and ice acidities in the new NEEM S1 core (Sigl et al., 2013). In particular it seemed reasonable to ask if the spacing intervals $3: 110.1: 34.9$ that are clearly there in the Law Dome acidities can be recognized in NEEM S1? Table 2 shows the comparison of spacing intervals between frost-damaged rings in bristlecone pine and spacing intervals between acid in the NEEM S1 core across the sixth and seventh century. It is immediately obvious that NEEM S1 acidities at AD 678, 567 and 529.8 provide us with the spaced intervals $111: 34.5$, but NEEM S1 seems not to pick up another acidity 3 years after their 678 date. Irrespective of that failing, we can see an entirely self-consistent spaced set of both frost rings and NEEM S1 acidities from NEEM S1 date range 686.4 to 515.5 and frost ring range AD 694 to 522 . However, the coherent picture only works with all the ice acidities moved forward in time by an average of 7.04 years.

If the ice core acidity dates were moved by 7 years, the resulting alignments would make sense of what was formerly a muddied picture. It becomes possible to see which volcanoes gave rise to frost rings and which frost rings appear to be un-associated. Note how the spacing tells us that Law Dome is picking up volcanoes at 687, 684, 574 and 541 while NEEM S1 registers 694, 684, 574 and 541. This makes sense with 684, 574 and 541 being equatorial, while 694 and 681 are more likely Northern Hemisphere, and 687 more likely southern. The implication being that if the ice core acidity dates were to be moved, their comparison with phenomena such as frost rings would produce a highly coherent picture regarding volcanoes and their environmental effects.

\section{Implications}

Given this potential upheaval in the GICC05 ice core chronology, there would be certain knock-on effects. Plummer et al. (2012) state that their chronology was independently dated via annual layer counting and their acidity list bears remarkable similarity to the independent Greenland NGRIP chronology. This replication should imply that the ice chronologies are robust. However, from Tables 1 and 2 we can see that suggested linkages to spaced frost ring dates imply that Law Dome and NEEM S1 may both be in error by around 7 years. Suggesting that an Antarctic core may also be too old makes it particularly interesting when we turn to another Antarctic core, WDC06A. Sigl et al. (2013) explain their approach to dating this ice core in detail; they say this:

In addition to the bi-hemispheric volcanic events used for the WDC06A timescale, the absolute ages were constrained by additional historic volcanic events in $1783,1477,1105,934 \pm 2$, and 79 . To be consistent with the high precision GICC05 Greenland ice core timescale, we used additional volcanic events from NorthGRIP [Plummer et al. (2012)] to guide the annual layer identification process for ambiguous layers. Thus, NEEM S1 is closely linked to NorthGRIP and thereby to the GICC05 timescales within \pm 1 year during all major common volcanic events. This is at the cost of independence of the NEEM S1 ice core timescale.

Here we are being told that NEEM S1 is linked to NGRIP and through bi-hemispheric volcanic events to WDC06A, and, further, that all this consistency is at the cost of a loss of independence. We are even told that this loss is a price worth paying:

The decision for consistency at a cost of independence is justified given the high dating accuracy of the GICC05 timescale, which does not exceed \pm 2 years in the last 2000 years [Larsen et al. (2008); Vinther et al. (2006)].

Table 3 summarizes the spacing between acidity in three Antarctic ice cores within the sixth and seventh centuries, and compares them with the spaces between bristlecone pine frost rings. Reviewing Tables $1-3$, and assuming that the suggested ice dating offset is corrected, it is then possible to make some deductions with respect to volcanoes that show up as acidities in one or both hemispheres. For example, the eruption signified as 541 by the frost rings most likely occurred in 540 as witnessed by effects starting in that year in Irish and European trees (Baillie, 1994). It appears to be equatorial as it occurs in both Greenland and Antarctic ice. Its dating coincides remarkably with the arrival of plague into Europe at the time of Justinian. It is notably separate from the historically recorded 536 dust veil (Stothers and Rampino, 1983) that shows up in all the main Northern Hemisphere cores, and only in WDC06A in Antarctica. It is interesting that Larsen et al. (2008) in discussing the acidity that they attributed to $\mathrm{AD} 529 \pm 2$, and which we are now suggesting should link to AD 536, attributed it to a Northern Hemisphere eruption. To complete that logic chain, Larsen et al. (2008) cited a Northern Hemisphere eruption in 529 \pm 2 and an equatorial eruption in 533-534 \pm 2 and sought to move these so that the latter caused the 536 events. We can now see that by moving their two eruptions to 536 and 540-541 we would be able to explain the Greenland bias of a northern eruption in 536 and the bi-polar acid distribution of a major equatorial eruption in 540-541, the latter, for example, making sense of the abrupt growth downturn after 540 in 
Table 2. Comparison of intervals between frost ring dates (Salzer and Hughes, 2007) and NEEM S1 acid start dates (Sigl et al., 2013). The values between successive diamonds $(\checkmark)$ in each column are the intervals between specific frost ring dates and specific ice acid dates. The similarity of the intervals suggests that the dates marked in bold are signals of the same event, indicating that ice core dates in this period are 7 years too old.

\begin{tabular}{|c|c|c|c|c|c|c|c|c|c|}
\hline $\begin{array}{l}\text { Frost } \\
\text { rings }\end{array}$ & & & & & $\begin{array}{l}\text { NEEM S1 } \\
\text { dates }\end{array}$ & & & & \\
\hline & & & & & 690.4 & & & & \\
\hline 694 & & & $\diamond$ & $\diamond$ & 686.4 & & & $\diamond$ & $\diamond$ \\
\hline 692 & & & & & & & & & \\
\hline 687 & & & & 10.0 & & & & & 8.4 \\
\hline \multirow{6}{*}{$\begin{array}{l}\mathbf{6 8 4} \\
\mathbf{6 8 1} \\
674\end{array}$} & & 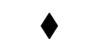 & & 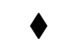 & 678.0 & & $\diamond$ & & $\diamond$ \\
\hline & $\diamond$ & & & & 674.4 & 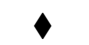 & & & \\
\hline & & & & & & & & & \\
\hline & & & & 57.0 & 630.1 & & & & 58.9 \\
\hline & & & & & 624.8 & & & & \\
\hline & & & 120.0 & & & & & 119.4 & \\
\hline \multirow[t]{4}{*}{627} & & 110.0 & & $\diamond$ & 619.1 & & 111.0 & & $\diamond$ \\
\hline & 107.0 & & & & & 107.4 & & & \\
\hline & & & & 53.0 & & & & & 52.1 \\
\hline & & & & & 582.3 & & & & \\
\hline \multirow[t]{3}{*}{574} & $\diamond$ & 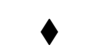 & $\diamond$ & $\vartheta$ & 567.0 & $\diamond$ & $\diamond$ & $\diamond$ & $\diamond$ \\
\hline & 33.0 & & & & & 34.5 & & & \\
\hline & & 38.0 & & & 539.35 & & 37.2 & & \\
\hline 541 & $\diamond$ & & & & 532.5 & $\diamond$ & & & \\
\hline 536 & & 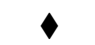 & & 52.0 & 529.8 & & 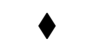 & & 51.5 \\
\hline \multirow[t]{3}{*}{532} & & & & & & & & & \\
\hline & 19.0 & & & & & 17.0 & & & \\
\hline & & 14.0 & & & & & 14.3 & & \\
\hline 522 & $\diamond$ & $\diamond$ & & $\diamond$ & 515.5 & $\diamond$ & $\diamond$ & & $\diamond$ \\
\hline
\end{tabular}

Table 3. Intervals between bristlecone pine frost rings (Salzer and Hughes, 2007) and intervals between acid start dates in three Antarctica ice cores; WDC06A (Sigl et al., 2013), Law Dome (Plummer et al., 2012) and DML (Traufetter et al., 2004). For clarity the value of the interval in each record is marked in bold. The consistent spacing suggests that the ice dates should be moved to conform to the tree ring dates.

\begin{tabular}{|c|c|c|c|c|c|c|c|}
\hline $\begin{array}{c}\text { Frost ring } \\
\text { date }\end{array}$ & $\begin{array}{c}\text { Frost ring } \\
\text { space }\end{array}$ & WDC06A & $\begin{array}{c}\text { WDC06A } \\
\text { space }\end{array}$ & Law Dome & $\begin{array}{c}\text { Law Dome } \\
\text { space }\end{array}$ & DML & $\begin{array}{l}\text { DML } \\
\text { space }\end{array}$ \\
\hline 687 & & & & 679.2 & & & \\
\hline & 3 & & & & 2.7 & & \\
\hline 684 & & 676.5 & & 676.5 & & & \\
\hline & 3 & & 2.4 & & & & \\
\hline 681 & & 674.1 & & & & 685 & \\
\hline & 107 & & 108.3 & & 110.2 & & 107 \\
\hline 574 & & 565.8 & & 566.3 & & 578 & \\
\hline & 33 & & 34.6 & & 35.4 & & 36 \\
\hline 541 & 5 & 531.2 & 2.5 & 530.9 & & 542 & \\
\hline 536 & & 528.7 & & & & & \\
\hline
\end{tabular}


trees from Argentina (Boninsegna and Holmes, 1985; Baillie, 2008). One additional benefit of moving the acidity dates forward to 536 and $540-541$ is that it would help to explain the extended environmental effects in tree records as cited by Larsen et al. (2008) as lasting from 536 to at least 550 . While we note that our interpretation would require the Law Dome acidity at $530.9_{-5}^{+1}$ to have to move 9 or 10 years to coincide with the 540 tree ring effects, it must be remembered that more than one eruption may have occurred in or around $\mathrm{AD} 540$, something that again might help to explain the prolonged effects.

We have noted above justification for our restriction of the spaced analysis to the period AD 500-700, and the poor linkages between acid dates and frost rings in the earlier centuries AD 100-500. There is however an alternative approach for testing ice acid and tree ring offsets. If we turn to Stothers and Rampino (1983) and their trawl of Mediterranean historical records, the only volcanoes before $\mathrm{AD} 700$ that are known to have produced significant environmental effects as recorded by humans across Eurasia (being recorded in both Europe and China) were those at 44 BC (Stothers and Rampino, 1983; Pang, 1991), AD 536 (Stothers and Rampino, 1983; Keys, 1999) and AD 626 (Stothers and Rampino, 1983; Fei et al., 2007). Bristlecone pine frost rings occur in $43 \mathrm{BC}, \mathrm{AD}$ 536 and AD 627. Thus we have three historically recorded, severe, dust veil events represented by frost rings and other tree effects spaced 579/580 and 90/91 years apart. If we turn to the Greenland ice records we have three notable acidities in GICC05 timescale starting at 51 BC, AD 529 and AD 619 (Vinther et al., 2006) with average $\mathrm{SO}_{4}^{2-}$ deposition values (in units of $\mathrm{Kg} \mathrm{Km}^{-2}$ ) of 122 (Clausen et al., 1997), 72 and 63 (Clausen et al., 1997; Sigl et al., 2013) respectively. These are the three largest replicated acid deposition values between AD 933 and 1074 BC and they are spaced 580 and 90 years apart; identical to the historical and frost ring spacing. Given that these three events had extended environmental effects that were recorded widely, that they show up clearly as frost rings and other tree effects, and that large volcanic acid layers in Greenland ice exhibit the same spacing (albeit systematically offset by around 7 years) suggests that these events are a robust test of the ice chronologies. We note that this spaced analysis draws particular attention to the issue of the $44 \mathrm{BC}$ historical dust veil and whether or not it relates to the large acidity at GICC05 51 BC (Vinther et al., 2006). Thus more detail is necessary at this point.

\section{More detailed records across $50 \mathrm{BC} / 44-40 \mathrm{BC}$}

Although the American GISP2 record has not featured in this paper thus far, it provides critical evidence when it comes to validating the Dye3, GRIP and NGRIP (and thus GICC05) observation of an extended volcanic signal around $50 \mathrm{BC}$. GISP2 has a large acidity at depth $480.8-481.25 \mathrm{~m}$ which is dated by Zielinski et al. (1994) to a minimum range of
54-51.6 BC. We say minimum range because sulfate values are already elevated above background by $481.25 \mathrm{~m}$ and are still elevated after $480.8 \mathrm{~m}$, thus the duration of the depositional event is at least 2.4 years. This is highly consistent with observation of the same layer in the GRIP core dated to $49 \mathrm{BC}$ and stated as having a duration of 2.7 years (Clausen et al., 1997). The question is, what is the actual date range of this acidity? We know from Zielinski (1995) that a layer at depth $453.49-453.95 \mathrm{~m}$ in GISP2 was assigned to Vesuvius because it was "within ten years" of where acid from Vesuvius might have been expected, and this assignment dictated the date given for the large acidity at $480.8-481.25 \mathrm{~m}$. What is not in doubt is that the 2.4/2.7 year acidity around 50-53 $\mathrm{BC}$ is the same layer in both cores.

The significance of the duration of this acid event (2.4 2.7 years) is that it matches extremely well with the historical accounts of the dimming of the sun observed from the Mediterranean and China between 44 and 42 BC. Stothers and Rampino (1983) deduced from Mediterranean sources that there were "unusual atmospheric phenomena" from 44 $42 \mathrm{BC}$ consistent with a volcanic dust veil and specifically an eruption of Etna, Sicily. That record parallels detailed Chinese observations which include a red daylight comet in 44 $\mathrm{BC}$, implying that the atmosphere was obscured by volcanic dust in that year (Horgan, 1987). This continued through 43 $\mathrm{BC}$ with the sun being pale blue and lacking brilliance, while frosts damaged crops leading to widespread famine. After a recovery in late $43 \mathrm{BC}$, by early $42 \mathrm{BC}$ "the sun, moon and the stars (were described as) veiled and indistinct.... By the time the volcano calmed down, six harvests had failed in China" (Pang, 1991).

The reason for rehearsing this detailed information is that we can say with some certainty that there was an extended, historically recorded, dust veil, probably comprising more than one eruption between spring $44 \mathrm{BC}$ and spring 42 . This ties in with ring width observations on foxtail pines from the Sierra Nevada of "a large decrease between 44 and 43 BC and continued decreased ring width values in both 42 and 41 BC" (Scuderi, 1990). Evidence consistent with a bristlecone pine frost ring in 43 BC (Salzer and Hughes, 2007) and notably reduced growth in Swedish temperature-sensitive pines from 43 to 40 BC (Grudd et al., 2002; Esper et al., 2012). Thus the replicated ice core evidence, around $50 \mathrm{BC}$, for an acid deposition event spanning around 3 years, is offset in time from one of the best-recorded dust veil events in ancient history that spans 44-42 BC, something implicit in comments by Stothers and Rampino (1983):

Further evidence of a great 44 B.C. eruption comes from a time record of acidity in a Greenland ice core analysed by Hammer et al. (1980). A strong 3 -year acidity peak was dated by them at about $50 \pm 30$ B.C. and has been confirmed at ca. 40 B.C. in another ice core by Herron (1982). 
Given that Herron's date ca. $40 \mathrm{BC}$ was moved to $50 \pm 4$ BC by Hammer (1984) this 50-44 BC offset has been evident for 30 years. Thus it was a known issue long before the offset of around 7 years between bristlecone pine frost ring dates and ice acidity dates were noted in the 6th century (Baillie, 2008) and reinforced for the sixth and seventh centuries in this paper.

\section{The complex AD 930's Eldgjá story}

If the suggestion of a 7-year offset between tree ring and ice core chronologies is correct, and occurs above AD 700, then this could have implications for the dating of "historical" volcanoes. When we compare historical records with both GICC05 and GISP2 we find good agreement from the present day down to at least the AD 1104 eruption attributed to Hekla. Before this date, serious disagreement in the dating of events begins to occur, as exemplified by the Eldgjá issue. While GICC05 favours a date of $933 \pm 1$, which is in line with the historically reconstructed date of AD 934 (Stothers, 1998), GISP2 locates Eldgjá at $938 \pm 4$ (Zielinski et al., 1994). Given that there is a bristlecone pine frost ring at AD 934 (Salzer and Hughes, 2007), it would be reasonable to think that GICC05, trees, and history are telling the same story of a large eruption of Eldgjá in AD 934. However, historical sources also tell us that around AD 939, the climate deteriorated with records of harsh winters (Stothers, 1998), with harsh cold weather lasting for 3 years (Fei and Zhou, 2006) supported by evidence of hemispheric cooling from European tree rings, whilst McCarthy and Breen (1997) and Oman et al. (2006) have also argued for a later date of 939 for Eldgjá.

What is apparent from this brief survey is that the dating of Eldgjá is not settled, and is further complicated by a recent paper by Sun et al. (2014). In that paper, results are presented which identify tephras from Eldgjá and the so-called Millennium eruption (Tianchi; China/North Korea) in both the GRIP and NEEM S1 cores, separated by seven annual layers. Thus, the Millennium eruption can be either dated to AD $941 \pm 1$ (GICC05 timescale) or to AD $945 \pm 4$ (GISP2 chronology). Taken at face value this result does not permit the definitive dating of Eldgjá, but does seemingly support the GICC05 timescale, since we now have a volcano 7 years after Eldgjá which could be responsible for the circa AD 940 climatic downturn. However, a complication arises due to historical accounts of unusual sonic phenomena described as "thunders like a drum" in Japan and Korea, and "white ash rain" in Japan during the winter of AD 946-947 (Xu et al., 2013). Japan is "downwind" of Tianchi, evidenced by tephra from the Millennium eruption located across the Japan sea and on island Japan (Machida and Arai, 1983; Hughes et al., 2013). Furthermore, records of Chinese weather (Fei and Zhou, 2006, Fig. 2) tell us that the winters of the years following AD 934 were not unusually cold, and were snow- less, until 939 when there was snow in July, and again in 939-940, which coincided with the coldest years in the time period 923-954. Furthermore, the years AD 945-948 are also noted to have been cold.

To place this in the context of our proposed tree-ring/ice core chronology offset, we observe in Chinese weather records, supported by European tree ring evidence, two spaced cold events occurring approximately 6 or 7 years apart that could be volcanically induced, mirroring the observed spaced tephra in ice core stratigraphy, thereby suggesting that Eldgjá may have erupted around AD 939, in line with the GISP2 chronology, with the direct implication that GICC05 is approximately 6 years too old at this particular depth. Such an implication was not lost on Sun et al. (2014) who concluded their paper; "On the basis of a stratigraphic ( $\sim 7$ years) offset, we can nevertheless distinguish the Millennium eruption from the major Eldgjá eruption which remains a contender for a volcanic source of the climate perturbations at AD 939-940."

Thus it would seem that the complexity of dating the Eldgjá eruption has been recognized, and the possibility has even been considered that its date may have to move forward in time by around 6 years. If that were to prove the case, any error in the overall GICC05 chronology would have to lie above AD 940.

\section{Conclusion}

It has been evident for some time that a discrepancy has existed in the first millennium between evidence for volcanoes in Greenland (and now Antarctic) ice cores, when compared with likely volcanic effects as witnessed by frost damage in American bristlecone pine trees - the offset being of the order of seven years with the ice dates being too old (Baillie, 2008). Here we have shown that remarkably consistent spacing between both the ice acidities and the frost rings allow additional documentation of this widespread offset. It has been possible to reconstruct how the ice cores from Dye3, GRIP, NGRIP, NEEM S1 and WDC06A can be regarded as an integrated group, in that they all tell the same underlying chronological story, with Law Dome, which is claimed to be independently dated, also conforming to the same ice chronology. It appears that they may well all be offset from real time as exemplified by the chronology of bristlecone pine frost rings, with only the DML core apparently showing less of an effect.

In this paper we have documented the need for re-dating most of the ice core chronologies for the period before AD 700 , and in all probability up to $\mathrm{AD} 933 \pm 1$. How far above this date the proposed error occurs remains for future analysis. Of necessity, if this proposed error is correct, the recent location and analysis of tephra in the GRIP core, and its attribution to Vesuvius, would have to be seen as flawed; something implicit in the less than absolute attribution of the alleged Vesuvius tephra (Barbante et al., 2013). 
Finally, if this re-dating is substantiated, a whole new chapter in the interpretation of past volcanism and its effects on trees and humans will be opened up. In particular it will finally be possible to tease out which volcanoes produced significant environmental effects, and which did not in the first millennium $\mathrm{AD}$ and earlier. It has been shown that bristlecone pine frost rings are not perfect recorders of the environmental effects of volcanic eruptions; however, the results given show that in conjunction with historical documentation and ice acidity measurements they form an important part of the story; in particular, they appear to be excellent recorders of the eruptions that most affected human populations such as those at $44 \mathrm{BC}$, AD 536 and AD 626.

\section{The Supplement related to this article is available online at doi:10.5194/cp-11-105-2015-supplement.}

Acknowledgements. The authors wish to acknowledge the helpful and constructive comments by reviewers Bo Vinther and the anonymous referee. We also thank Copernicus Publications Editorial Support for assistance with the Article Processing Charges.

Edited by: V. Masson-Delmotte

\section{References}

Arjava, A.: The mystery cloud of the year $536 \mathrm{CE}$ in the Mediterranean sources, Dumbarton Oaks Papers, 59, 73-94, 2005.

Baillie, M. G. L.: Dendrochronology raises questions about the nature of the AD 536 dust-veil event, The Holocene, 4, 212-217, 1994.

Baillie, M. G. L.: Proposed re-dating of the European ice core chronology by seven years prior to the 7th century AD, Geophys. Res. Lett., 35, L15813, doi:10.1029/2008GL034755, 2008.

Baillie, M. G. L.: Volcanoes, ice-cores and tree-rings: one story or two?, Antiquity, 84, 202-215, 2010.

Barbante, C., Kehrwald, N. M., Marianelli, P., Vinther, B. M., Steffensen, J. P., Cozzi, G., Hammer, C. U., Clausen, H. B., and Siggaard-Andersen, M.-L.: Greenland ice core evidence of the 79 AD Vesuvius eruption, Clim. Past, 9, 1221-1232, doi:10.5194/cp-9-1221-2013, 2013.

Barras, C.: AD 536: the year that winter never ended, New Scientist, 20 January, 34-38, 2014.

Boninsegna, J. A. and Holmes, R. L.: Fitzroya cupressoides yields 1534-year long South American chronology, Tree Ring Bull., 45, 37-42, 1985.

Briffa, K. R., Jones, P. D., Schweingruber, F. H., and Osborn, T. J.: Influence of volcanic eruptions on Northern Hemisphere summer temperature over the past 600 years, Nature, 393, 450-455, 1998.

Clausen, H. B., Hammer, C. U., Hvidberg, C. S., Dahl-Jensen, D., Steffensen, J. P., Kipfstuhl, J., and Legrand, M.: A comparison of the volcanic records over the past 4000 years from the Greenland Ice Core Project and Dye 3 Greenland ice cores, J. Geophys. Res., 102, 26707-26723, 1997.
D’Arrigo, R., Wilson, R., and Anchukaitis, K. J.: Volcanic cooling signal in tree ring temperature records for the past millennium, $\mathrm{J}$ Geophys. Res.-Atmos., 118, 9000-9010, 2013.

Esper, J., Frank, D. C., Timonen, M., Zorita, E., Wilson, R. J. S., Luterbacher, J., Holzkäper, S., Fischer, N., Wagner, S., Nievergelt, D., Verstege, A., and Büntgen, U.: Orbital forcing of treering data, Nature Clim. Change, 2, 862-866, 2012.

Fei, J. and Zhou, J.: The possible climatic impact in China of Iceland's Eldgjá eruption inferred from historical sources, Clim. Change, 76, 443-457, 2006.

Fei, J., Zhou, J., and Hou, Y.: Circa A.D. 626 volcanic eruption, climatic cooling, and the collapse of the Eastern Turkic Empire, Clim. Change, 81, 469-475, 2007.

Ferris, D. G., Cole-Dai, J., Reyes, A. R., and Budner, D. M.: South Pole ice core record of explosive volcanic eruptions in the first and second millennia A.D. and evidence of a large eruption in the tropics around 535 A.D., J. Geophys. Res., 116, D17308, doi:10.1029/2011JD015916, 2011.

Grudd, H., Briffa, K. R., Karlén, W., Bartholin, T. S., Jones, P. D., and Kromer, B.: A 7400-year tree-ring chronology in northern Swedish Lapland: Natural climate variability expressed on annual to millennial time scales, The Holocene, 12, 657-665, 2002.

Gunn, J. D. (Ed.): The Years without Summer: Tracing AD 536 and its Aftermath (British Archaeological Reports (BAR) International), Archaeopress, Oxford, 2000.

Hammer, C. U.: Traces of Icelandic eruptions in the Greenland Ice Sheet, Jökull, 34, 51-65, 1984.

Hammer, C. U., Clausen, H. B., and Dansgaard, W.: Greenland ice sheet evidence of post-glacial volcanism and its climatic impact, Nature, 288, 230-235, 1980.

Herron, M. M.: Impurity sources of $\mathrm{F}^{-}, \mathrm{Cl}^{-}, \mathrm{NO}_{3}^{-}$and $\mathrm{SO}_{4}^{2-}$ in Greenland and Antarctic precipitation, J. Geophys. Res., 87, 3052-3060, 1982.

Horgan, J.: Volcanic winter, Sci. Am., 2, 83-84, 1987.

Hughes, P. D., Mallon, G., Brown, A., Essex, H. J., Stanford, J. D., and Hotes, S.: The impact of high tephra loading on late-Holocene carbon accumulation and vegetation succession in peatland communities, Quaternary Sci. Rev., 67, 160-175, 2013.

Jones, P. D., Melvin, T. M., Harpham, C., Grudd, H., and Helama, S.: Cool North European summers and possible links to explosive volcanic eruptions, J. Geophys. Res.-Atmos., 118, 6259-6265, 2013.

Keys, D.: Catastrophe: A Quest for the Origins of the Modern World, Ballantine Books Inc, 1999.

LaMarche, V. C. and Hirschboeck, K. K.: Frost rings in trees as records of major volcanic eruptions, Nature, 307, 121-126, 1984.

Larsen, L. B., Vinther, B. M., Briffa, K. R., Melvin, T. M., Clausen, H. B., Jones, P. D., Siggaard-Andersen, M.-L., Hammer, C. U., Eronen, M., Grudd, H., Gunnarson, B. E., Hantemirov, R. M., Naurzbaev, M. M., and Nicolussi, K.: New ice core evidence for a volcanic cause of the A.D. 536 dust veil, Geophys. Res. Lett., 35, L04708, doi:10.1029/2007GL032450, 2008.

Lavigne, F., Degeai, J.-P., Komorowski, J.-C., Guillet, S., Robert, V., Lahitte, P., Oppenheimer, C., Stoffel, M., Céline, M., Vidal, C. M., Surono, Pratomo, I., Wassmer, P., Hajdas, I., Hadmoko, D. S., and de Belizal, E.: Source of the great A.D. 1257 mystery eruption unveiled, Samalas volcano, Rinjani Volcanic Complex, Indonesia, P. Natl. Acad. Sci. USA, 110, 16742-16747, 2013. 
Machida, H. and Arai, F.: Extensive ash falls in and around the sea of Japan from large late Quaternary eruptions, J. Volcanol. Geotherm. Res., 18, 151-164, 1983.

McCarthy, D. and Breen, A.: An evaluation of astronomical observations in the Irish annals, Vista. As. S., 41, 117-138, 1997.

Oman, L., Robock, A., Stenchikov, G. L., and Thordarson, T.: High-latitude eruptions cast shadow over the African monsoon and the flow of the Nile, Geophys. Res. Lett., 33, L18711, doi:10.1029/2006GL027665, 2006.

Oppenheimer, C.: Eruptions that Shook the World, Cambridge University Press, Cambridge, 2011.

Pang, K. D.: The Legacies of Eruptions, The Sciences, 31, 30-33, 1991.

Plummer, C. T., Curran, M. A. J., van Ommen, T D., Rasmussen, S. O., Moy, A. D., Vance, T. R., Clausen, H. B., Vinther, B. M., and Mayewski, P. A.: An independently dated 2000-yr volcanic record from Law Dome, East Antarctica, including a new perspective on the dating of the 1450s CE eruption of Kuwae, Vanuatu, Clim. Past, 8, 1929-1940, doi:10.5194/cp-8-1929-2012, 2012.

Rampino, M. R. and Self, S.: Historic eruptions in Tambora (1815), Krakatau (1883), and Agung (1963), their stratospheric aerosols, and climatic impact, Quat. Res., 18, 127-143, 1982.

Salzer, M. W. and Hughes, M. K.: Bristlecone pine tree rings and volcanic eruptions over the last $5000 \mathrm{yr}$, Quat. Res., 67, 57-68, 2007.

Scuderi, L. A.: Tree-ring evidence for climatically effective volcanic eruptions, Quat. Res., 34, 67-85, 1990.

Sigl, M., McConnell, J. R., Layman, L., Maseli, O., McGwire, K., Pasteris, D., Dahl-Jensen, D., Steffenson, J. P., Vinther, B. M., Edwards, R., Mulvaney, R., and Kipfstuhl, S.: A new bipolar ice core record of volcanism from WAIS Divide and NEEM and implications for climate forcing of the last 2000 years, J. Geophys. Res., 118, 1151-1169, 2013.

Stothers, R. B.: Mystery cloud of AD 536, Nature, 307, 344-345, 1984.
Stothers, R. B.: Far reach of the tenth century Eldgjá eruption, Iceland, Clim. Change, 39, 715-726, 1998.

Stothers, R. B. and Rampino, M. R.: Volcanic eruptions in the Mediterranean before A.D. 630 from written and archaeological sources, J. Geophys. Res., 88, 6357-6371, 1983.

Sun, C., Plunkett, G., Lie, J., Zhao, H., Sigl, M., McConnell, J. R., Pilcher, J. R., Vinther, B., Steffensen, J. P., and Hall, V.: Ash from Changbaishan Millennium eruption recorded in Greenland ice: implications for determining the eruption's timing and impact, Geophys. Res. Lett., 41, 694-701, 2014.

Traufetter, F., Oerter, H., Fischer, H., Weller, R., and Miller, H.: Spatio-temporal variability in volcanic sulphate deposition over the past $2 \mathrm{kyr}$ in snow pits and firn cores from Amundsenisen, Dronning Maud Land, Antarctica, J. Glaciol., 50, 137-146, 2004.

Vinther, B. M., Clausen, H. B., Johnsen, S. J., Rasmussen, S. O., Andersen, K. K., Buchardt, S. L., Dahl-Jensen, D., Seierstad, I. K., Siggaard-Andersen, M. L., Steffensen, J. P., Svensson, A., Olsen, J., and Heinemeier, J.: A synchronized dating of three Greenland ice cores throughout the Holocene, J. Geophys. Res., 111, D13102, doi:10.1029/2005JD006921, 2006.

Xu, J., Pan, B., Liu, T. Z., Hajdas, I., Zhao, B., Yu, H. M., Liu, R. X., and Zhao, P.: Climatic impact of the Millennium eruption of Changbaishan volcano in China: New insights from highprecision radiocarbon wiggle-match dating, Geophys. Res. Lett., 40, 54-59, 2013.

Zielinski, G. A.: Stratospheric loading and optical depth estimates of explosive volcanism over the last 2100 years derived from the Greenland Ice Sheet Project 2 ice core, J. Geophys. Res., 100, 20937-20955, 1995.

Zielinski, G. A., Mayewski, P. A., Meeker, L. D., Whitlow, S., Twickler, M. S., Morrison, M., and Meese, D. A.: Record of volcanism since 7000 B.C. from the GISP2 Greenland ice core and implications for the volcano-climate system, Science, 264, 948952, 1994. 